\title{
Efficacy of Axitinib as Second-line Treatment in Locally Advanced and Metastatic Renal Cell Carcinoma
}

\author{
KOSUKE UEDA, SHIGETAKA SUEKANE, TAISHI HIRANO, \\ NAOYUKI OGASAWARA, KATSUAKI CHIKUI, KEIICHIRO UEMURA, MAKOTO \\ NAKIRI, KIYOAKI NISHIHARA, MITSUNORI MATSUO and TSUKASA IGAWA \\ Department of Urology, Kurume University School of Medicine, Kurume, Japan
}

\begin{abstract}
Aim: To investigate prognostic factors for patients with advanced renal cell carcinoma $(R C C)$ treated with axitinib as second-line therapy. Patients and Methods: This study included 35 patients with $R C C$ who received axitinib as second-line therapy after the failure of first-line tyrosine kinases inhibitor from November 2012 to March 2017. Results: In univariate analyses, the following factors were associated with poor prognosis: bone and extrapulmonary metastasis for progression-free survival; and prior nephrectomy, Memorial Sloan Kettering Cancer Center risk classification, International Metastatic Renal Cell Carcinoma Database Consortium (IMDC) risk classification of poor, extrapulmonary metastasis and early tumor response for overall survival. Multivariate analyses identified the following factors as independent poor prognostic effects: extrapulmonary metastasis for progression-free survival, and no prior nephrectomy, IMDC risk classification of poor and extrapulmonary metastasis for overall survival. Conclusion: Axitinib as second-line treatment is effective for patients with pulmonary metastasis alone of RCC, but not for those with extrapulmonary metastasis.
\end{abstract}

Renal cell carcinoma (RCC) accounts for approximately 3\% of adult malignancies and is the fourth most common urogenital malignancy in Japan $(1,2)$. For the last several years, the strategy for locally advanced and metastatic RCC has been changing to administration of molecular-targeted therapies, such as inhibitors of tyrosine kinases (TKIs) and mammalian target of rapamycin, instead of immunotherapy as the first-line therapy (3-5). These therapeutic agents have prolonged the survival of patients with $\operatorname{RCC}(6,7)$. However,

Correspondence to: Kosuke Ueda, M.D., Ph.D., Department of Urology, Kurume University School of Medicine, 67 Asahi-machi, Kurume 830-0011, Japan. Tel: +81 942317989, Fax: +81 942317866, e-mail: ueda_kousuke@med.kurume-u.ac.jp

Key Words: Renal cell carcinoma, axitinib, second-line therapy. the disease of the majority of patients with RCC will eventually fail to respond to first-line therapy as a result of progression or intolerable adverse effects (AEs) (8).

Axitinib, a second-generation targeted drug, is a potent and highly selective inhibitor of vascular endothelial growth factor (VEGF) receptor tyrosine kinase 1,2, and 3. The AXIS trial was the first randomized phase III study to compare two active VEGF-targeted agents, axitinib and sorafenib, for second-line therapy of advanced RCC (9). Compared with sorafenib, axitinib significantly improved progression-free survival (PFS) in the overall trial population, as well as in the subgroups of patients previously treated with sunitinib or cytokines.

In Japan, axitinib was approved in 2012 and has been widely accepted as an efficacious second-line treatment for patients with locally advanced and metastatic RCC. Previously, Miyake et al. demonstrated that the Memorial Sloan Kettering Cancer Center (MSKCC) risk classification (10) and C-reactive protein (CRP) are prognostic factors in patients with metastatic RCC receiving axitinib as second-line therapy (11). However, previous reports included many patients who received cytokines as first-line treatment, and almost no reports have discussed prognostic predictors in patients who received second-line axitinib after the failure of first-line TKI therapy.

In the present study, we aimed to investigate the prognostic factors for patients with locally advanced and metastatic RCC treated with axitinib as second-line therapy after the failure of first-line TKI.

\section{Materials and Methods}

Patients. Data for all patients with locally advanced and metastatic RCC who received axitinib as second-line therapy after the failure of first-line TKI at the Kurume University Hospital from November 2012 to March 2017 were analyzed. All patients who received at least one dose of axitinib were eligible. The clinical information of these patients was obtained from the medical records and was retrospectively reviewed and analyzed. This study was approved by the Ethics Review Committee at Kurume University School of Medicine (16227). 
Therapy. Axitinib was given according to standard recommendations (9) with a starting dose of $5 \mathrm{mg}$ twice daily ( $10 \mathrm{mg} /$ day). Whenever possible, dose titration was performed according to the standard dosing schedule. When patients experienced an intolerable AE, dose reduction was performed based on the same recommendations. Severity of AEs was graded according to Common Terminology Criteria for Adverse Events (CTCAE) version 4.0 (12).

PFS was defined as the time from the start of axitinib to the first documentation of progression or death from any cause. Overall survival (OS) was defined as the time from the start of axitinib therapy to death from any cause or last contact.

Radiological evaluations were performed for all patients by computed tomography (CT). Tumor response was evaluated as best response according to the Response Evaluation Criteria in Solid Tumours (RECIST) version 1.1 (13). Early tumor response on the first-follow up CT was evaluated at 4-12 weeks after the introduction of axitinib and a $10 \%$ decrease in diameter of the tumor was used as the cut-off value based on a previous report (14).

Statistical analysis. PFS and OS were determined using the KaplanMeier method, and analyzed using the log-rank test. To identify the prognostic factors associated with PFS and OS, Cox proportional hazards regression was used. Univariate and multivariate analyses were performed for independent prognostic factors for PFS and OS. The relationships between groups were compared using chi-squared test, Fisher's exact test or Student's $t$-test. All statistical analyses were performed using JMP version 13 (SAS Institute Inc., Cary, NC, USA) and a value of $p<0.05$ was considered to indicate a statistically significant difference.

\section{Results}

Patient characteristics. Patient characteristics are summarized in Table I. The median patient age was 66 years (range $=40-78$ years). The majority of patients were male (74.3\%). More than one-half of patients were in the intermediate-risk group, for both MSKCC and the International Metastatic Renal Cell Carcinoma Database Consortium (IMDC) classification (15) (74.3\% and $74.3 \%$, respectively). Axitinib was introduced as second-line therapy after the failure of first-line TKI. The most common first-line therapy was sunitinib, administered to $68.6 \%$ of patients. The median PFS on first-line therapy in the whole patient cohort was 7.7 months [95\% confidence interval $(\mathrm{CI})=0.5-56.0$ months].

Objective response rate. Complete response was not obtained as best response to axitinib. Partial response and stable disease were achieved in eight $(22.9 \%)$ and $18(51.4 \%)$ patients, respectively. However, the remaining nine $(25.7 \%)$ patients were judged to have progressive disease. Therefore, the objective response rate and the clinical benefit rate in this study were $22.9 \%$ and $74.3 \%$, respectively.

Outcomes after treatment with axitinib. PFS and OS after introducing treatment with axitinib were assessed. As shown in Figure 1, the median PFS and OS were 5.8 and 29.5 months, respectively. To identify the prognostic factors associated with
Table I. Patient characteristics.

\begin{tabular}{lc}
\hline Characteristic & All patients (n=35) \\
\hline Age, years & \\
Median (range) & $66(40-78)$ \\
Gender, $\mathrm{n}(\%)$ & \\
Male & $26(74.3 \%)$ \\
Female & $9(25.7 \%)$ \\
Prior nephrectomy, $\mathrm{n}(\%)$ & \\
Yes & $26(74.3 \%)$ \\
No & $9(25.7 \%)$ \\
MSKCC risk classification, $\mathrm{n}(\%)$ & \\
Favorable & $4(11.4 \%)$ \\
Intermediate & $26(74.3 \%)$ \\
Poor & $5(14.3 \%)$ \\
IMDC risk classification, $\mathrm{n}(\%)$ & \\
Favorable & $3(8.6 \%)$ \\
Intermediate & $26(74.3 \%)$ \\
Poor & $6(17.1 \%)$ \\
Metastatic sites, $\mathrm{n}(\%)$ & \\
Lung & $21(60 \%)$ \\
Bone & $11(31.4 \%)$ \\
Liver & $4(11.4 \%)$ \\
Number of organs with metastasis, $\mathrm{n}(\%)$ & \\
1 & $18(51.4 \%)$ \\
2 & $8(22.9 \%)$ \\
$\geq 3$ & $9(25.7 \%)$ \\
Histology of primary tumor, $\mathrm{n}(\%)$ & $22(62.9 \%)$ \\
CCRCC & $5(14.3 \%)$ \\
Non-CCRCC & $8(22.9 \%)$ \\
Unknown & \\
First-line treatment, $\mathrm{n}(\%)$ & $6(68.6 \%)$ \\
Sunitinib & $5(14.1 \%)$ \\
Sorafenib & \\
Pazopanib & \\
PFS on first-line treatment, months & \\
Median (range) & \\
\hline & \\
& \\
&
\end{tabular}

MSKCC: Memorial Sloan Kettering Cancer Center; IMDC: International Metastatic Renal Cell Carcinoma Database Consortium; CCRCC: clear cell renal cell carcinoma; PFS: progression-free survival.

PFS and OS, univariate and multivariate analyses were performed using the Cox proportional hazards model (Tables II and III). Univariate analyses identified the following factors as being significantly associated with a poor prognosis, with two-fold hazard ratios or more: bone metastasis $(p=0.0287)$ and extrapulmonary metastasis $(p=0.0005)$ for PFS; and prior nephrectomy $(p=0.0229)$, MSKCC risk classification $(p=0.0076)$, IMDC risk classification of poor $(p=0.0011)$, extrapulmonary metastasis $(p=0.0336)$ and early tumor response $(p=0.0221)$ for OS. Multivariate analyses of these significant prognosticators were performed, and the following factors demonstrated independent prognostic effects: extrapulmonary metastasis $(p=0.0037)$ for PFS, and prior nephrectomy $(p=0.0449)$, IMDC risk classification of poor $(p=0.0217)$ and extrapulmonary metastasis $(p=0.0020)$ for OS. 
A

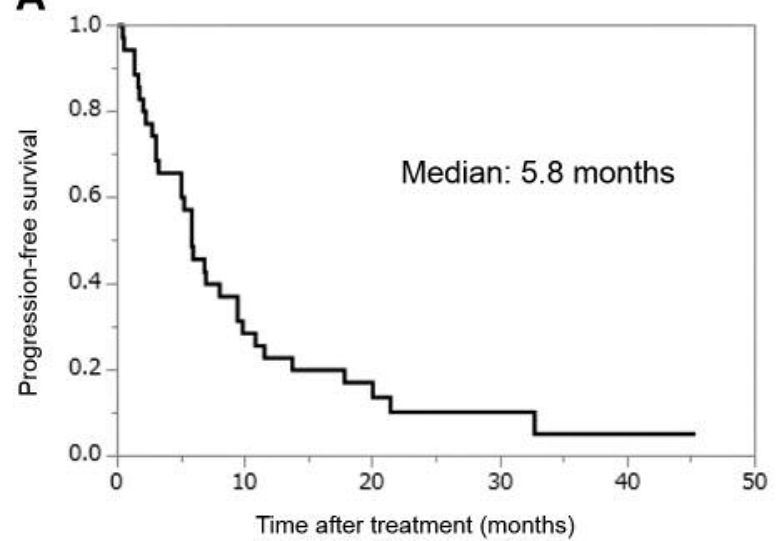

B

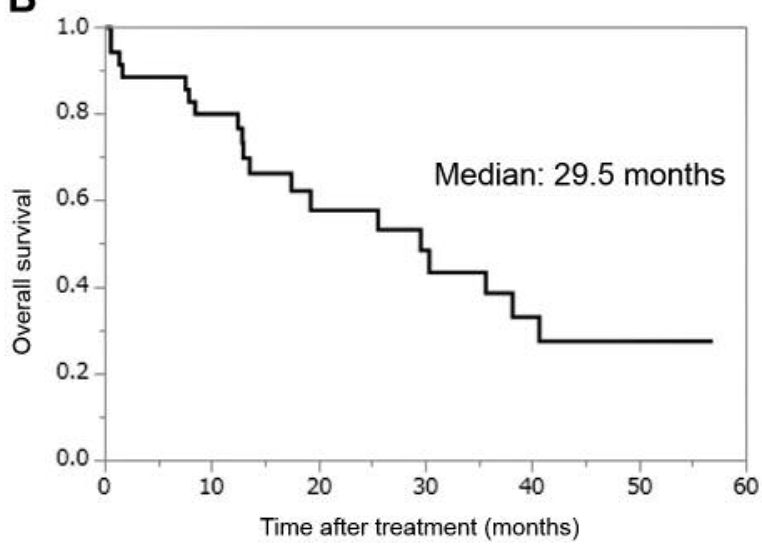

Figure 1. Progression-free survival (A) and overall survival (B) in patients with advanced renal cell carcinoma treated with axitinib as second-line therapy.

Table II. Univariate and multivariate analyses of progression-free survival in patients with advanced renal cell carcinoma treated with axitinib as second-line therapy $(n=35)$.

\begin{tabular}{|c|c|c|c|c|}
\hline \multirow[b]{2}{*}{ Variable } & \multicolumn{2}{|c|}{ Univariate analysis } & \multicolumn{2}{|c|}{ Multivariate analysis } \\
\hline & $\mathrm{HR}(95 \% \mathrm{CI})$ & $p$-VaIue & $\mathrm{HR}(95 \% \mathrm{CI})$ & $p$-VaIue \\
\hline \multicolumn{5}{|l|}{ Age } \\
\hline$<66$ Years & 1 & & & \\
\hline$\geq 66$ Years & $0.990(0.493-2.030)$ & 0.9780 & & \\
\hline \multicolumn{5}{|l|}{ Gender } \\
\hline Male & 1 & & & \\
\hline Female & $1.571(0.684-3.313)$ & 0.2716 & & \\
\hline \multicolumn{5}{|l|}{ Prior nephrectomy } \\
\hline Yes & 1 & & & \\
\hline No & $1.861(0.798-4.024)$ & 0.1435 & & \\
\hline \multicolumn{5}{|l|}{ MSKCC risk classification } \\
\hline Favorable or intermediate & 1 & & & \\
\hline Poor & $1.080(0.361-2.634)$ & 0.8780 & & \\
\hline \multicolumn{5}{|l|}{ IMDC risk classification } \\
\hline Favorable or intermediate & 1 & & & \\
\hline Poor & $1.480(0.544-3.439)$ & 0.4139 & & \\
\hline \multicolumn{5}{|l|}{ CRP } \\
\hline$<1.0 \mathrm{mg} / \mathrm{dl}$ & 1 & & & \\
\hline$\geq 1.0 \mathrm{mg} / \mathrm{dl}$ & $1.822(0.882-3.750)$ & 0.1038 & & \\
\hline \multicolumn{5}{|l|}{ Metastatic site } \\
\hline Pulmonary alone & 1 & & 1 & \\
\hline Extrapulmonary & $5.391(1.989-18.952)$ & 0.0005 & $4.693(1.610-17.113)$ & 0.0037 \\
\hline \multicolumn{5}{|l|}{ Bone metastasis } \\
\hline No & 1 & & 1 & \\
\hline Yes & $2.424(1.102-5.083)$ & 0.0287 & $1.437(0.631-3.197)$ & 0.3793 \\
\hline \multicolumn{5}{|l|}{ Number of organs with metastasis } \\
\hline 1 & 1 & & & \\
\hline$\geq 2$ & $1.935(0.918-4.216)$ & 0.0828 & & \\
\hline \multicolumn{5}{|l|}{ PFS on first-line TKI } \\
\hline$<6$ Months & 1 & & & \\
\hline$\geq 6$ Months & $1.476(0.726-3.068)$ & 0.2826 & & \\
\hline \multicolumn{5}{|l|}{ Early tumor response } \\
\hline$\geq 10 \%$ shrinkage & 1 & & & \\
\hline Progression or $10 \%$ shrinkage & $2.163(0.979-5.457)$ & 0.0569 & & \\
\hline
\end{tabular}

HR: Hazard ratio; CI: confidence interval; MSKCC: Memorial Sloan Kettering Cancer Center, IMDC: International Metastatic Renal Cell Carcinoma Database Consortium, CRP: C-reactive protein, PFS: progression-free survival, TKI: tyrosine kinase inhibitor, PR: partial response, SD: stable disease, PD: progressive disease. 
Table III. Univariate and multivariate analyses of overall survival in patients with advanced renal cell carcinoma treated with axitinib as secondline therapy $(n=35)$.

\begin{tabular}{|c|c|c|c|c|}
\hline \multirow[b]{2}{*}{ Variable } & \multicolumn{2}{|c|}{ Univariate analysis } & \multicolumn{2}{|c|}{ Multivariate analysis } \\
\hline & HR $(95 \% \mathrm{CI})$ & $p$-VaIue & HR $(95 \% \mathrm{CI})$ & $p$-VaIue \\
\hline \multicolumn{5}{|l|}{ Age } \\
\hline$<66$ Years & 1 & & & \\
\hline$\geq 66$ Years & $1.065(0.438-2.692)$ & 0.8910 & & \\
\hline \multicolumn{5}{|l|}{ Gender } \\
\hline Male & 1 & & & \\
\hline Female & $1.585(0.553-4.047)$ & 0.3694 & & \\
\hline \multicolumn{5}{|l|}{ Prior nephrectomy } \\
\hline Yes & 1 & & 1 & \\
\hline No & $3.409(1.197-9.338)$ & 0.0229 & $3.988(1.033-15.545)$ & 0.0449 \\
\hline \multicolumn{5}{|l|}{ MSKCC risk classification } \\
\hline Favorable or intermediate & 1 & & 1 & \\
\hline Poor & $5.392(1.638-15.842)$ & 0.0076 & $1.175(0.236-5.497)$ & 0.8375 \\
\hline \multicolumn{5}{|l|}{ IMDC risk classification } \\
\hline Favorable or intermediate & 1 & & 1 & \\
\hline Poor & $7.266(2.342-21.368)$ & 0.0011 & $6.561(1.325-33.635)$ & 0.0217 \\
\hline \multicolumn{5}{|l|}{ CRP } \\
\hline$<1.0 \mathrm{mg} / \mathrm{dI}$ & 1 & & & \\
\hline$\geq 1.0 \mathrm{mg} / \mathrm{dI}$ & $1.931(0.770-4.922)$ & 0.1587 & & \\
\hline \multicolumn{5}{|l|}{ Metastatic site } \\
\hline Pulmonary alone & 1 & & 1 & \\
\hline Extrapulmonary & $3.938(1.099-25.117)$ & 0.0336 & $12.849(2.272-131.245)$ & 0.0020 \\
\hline \multicolumn{5}{|l|}{ Bone metastasis } \\
\hline No & 1 & & & \\
\hline Yes & $2.301(0.835-5.906)$ & 0.1031 & & \\
\hline \multicolumn{5}{|l|}{ Number of organs with metastasis } \\
\hline 1 & 1 & & & \\
\hline$\geq 2$ & $2.422(0.889-7.662)$ & 0.0848 & & \\
\hline \multicolumn{5}{|l|}{ PFS on first-line TKI } \\
\hline$<6$ Months & 1 & & & \\
\hline$\geq 6$ Months & $0.837(0.335-2.122)$ & 0.7020 & & \\
\hline \multicolumn{5}{|l|}{ Early tumor response } \\
\hline$\geq 10 \%$ shrinkage & 1 & & 1 & \\
\hline Progression or $10 \%$ shrinkage & $4.229(1.209-26.699)$ & 0.0221 & $4.360(0.817-80.520)$ & 0.0920 \\
\hline
\end{tabular}

HR: Hazard ratio; CI: confidence intervaI; MSKCC: Memorial Sloan Kettering Cancer Center, IMDC: International Metastatic Renal Cell Carcinoma Database Consortium, CRP: C-reactive protein, PFS: progression-free survival, TKI: tyrosine kinase inhibitor, PR: partial response, SD: stable disease, PD: progressive disease.

AE profile of axitinib. Most AEs were grade 1 or 2 (Table IV). Fatigue and hypertension were the most common AEs. Common AEs corresponding to grade 3 or higher were hypertension $(11.4 \%)$, proteinuria $(11.4 \%)$, and diarrhea $(8.6 \%)$. However, there was no case of treatment-related death in this study.

Subsequent lines after treatment with axitinib. Of the 35 patients, three $(8.6 \%)$ remained under treatment with axitinib, while the remaining $32(91.4 \%)$ were unable to continue axitinib as a result of either disease progression (in 27,77.1\%) or intolerable AEs (in five, 14.3\%). Of the 32 patients who stopped receiving axitinib, nine (28.1\%), five (15.6\%), four $(12.5 \%)$, two $(6.3 \%)$, and one $(3.1 \%)$ were treated with everolimus, nivolumab, pazopanib, sorafenib, and sunitinib, respectively, as third-line therapy. Meanwhile, the remaining $11(34.4 \%)$ received best supportive care as a result of disease progression.

\section{Discussion}

Axitinib has been recognized as a standard second-line treatment in patients with locally advanced and metastatic RCC and first-line treatment failure $(11,16,17)$. However, there are few reports on the correlation between the treatment effect of second-line axitinib and prognostic predictors. Recently, treatment options have diversified since nivolumab was approved as second-line treatment for patients with first- 
Table IV. Treatment-related adverse effects in patients with advanced renal cell carcinoma treated with axitinib as second-line therapy $(n=35)$.

\begin{tabular}{lcc}
\hline Adverse effect & All grades, $\mathrm{n}(\%)$ & Grade $\geq 3, \mathrm{n}(\%)$ \\
\hline Fatigue & $18(51.4 \%)$ & $1(2.9 \%)$ \\
Hypertension & $16(45.7 \%)$ & $4(11.4 \%)$ \\
Anemia & $14(40.0 \%)$ & $2(5.8 \%)$ \\
Diarrhea & $13(37.1 \%)$ & $3(8.6 \%)$ \\
Decreased appetite & $9(25.7 \%)$ & $0(0.0 \%)$ \\
Hypothyroidism & $7(20.0 \%)$ & $0(0.0 \%)$ \\
Proteinuria & $6(17.1 \%)$ & $4(11.4 \%)$ \\
Hand-foot syndrome & $5(14.3 \%)$ & $1(2.9 \%)$ \\
Thrombocytopenia & $5(14.3 \%)$ & $1(2.9 \%)$ \\
Increased creatinine & $4(11.4 \%)$ & $1(2.9 \%)$ \\
Hematuria & $2(5.7 \%)$ & $0(0.0 \%)$ \\
Hoarseness & $2(5.7 \%)$ & $0(0.0 \%)$ \\
Cerebral hemorrhage & $1(2.9 \%)$ & $0(0.0 \%)$ \\
Heart failure & $1(2.9 \%)$ & $0(0.0 \%)$ \\
Oral mucositis & $1(2.9 \%)$ & $0(0.0 \%)$ \\
\hline
\end{tabular}

line TKI failure (18). The present study examined the treatment effect of second-line axitinib treatment and prognostic predictors in patients with first-line TKI failure.

The objective response rate in our study, $22.9 \%$, was slightly lower than those shown by previous reports $(9,19)$. This could be because many previous studies included patients treated with cytokine therapy as first-line treatment.

Miyake et al. reported that MSKCC risk classification and pretreatment CRP levels were the independent predictors of PFS in second-line axitinib therapy (11). In our study, there was no significant correlation between MSKCC risk classification or pretreatment CRP level and PFS of patients treated with axitinib. This can be partly accounted for by the fact that these reported studies had included patients who received cytokine therapy as first-line treatment, without being limited to patients with TKI failure. Previous reports have demonstrated that early tumor response to molecular targeted agents was involved in the prolongation of PFS or OS in the treatment of metastatic RCC $(14,20)$. Miyake et al. showed that early tumor shrinkage under treatment with a second-line molecular targeted therapy could serve as a useful parameter with an independent impact on OS in patients with metastatic RCC (21). In their reports, some molecular targeted agents, including axitinib as second-line therapy, were administrated to patients with metastatic RCC. In our study, the patients with $\geq 10 \%$ early tumor shrinkage tended to have a longer PFS with second-line axitinib compared with the patients with progression or less than $10 \%$ shrinkage. However, there was no significant difference between the two groups. A recent report demonstrated that longer response duration to first-line TKI was associated with longer PFS with second-line molecular targeted therapy (22). Li et al. showed that patients who responded to first-line sunitinib achieved fair disease control using second-line axitinib (23). However, Miyazaki et al. (24) also reported that the clinical response to second-line TKI therapy is not dependent on that to first-line TKI therapy in patients with metastatic RCC (24). In our study, no significant correlation was observed between the first-line treatment duration and PFS with second-line axitinib. In the sub-analysis of CheckMate 025 (25), nivolumab showed a higher treatment effect compared to everolimus in patients with bone or liver metastasis of RCC. Although this study was a retrospective single-arm study to explore the treatment outcome of axitinib and cannot simply be compared with nivolumab, as the treatment effect of second-line axitinib in patients with extrapulmonary metastasis was limited in our results, clinicians need to consider available treatment options including nivolumab. In our evaluation of OS, prior nephrectomy, IMDC risk classification of poor, and extrapulmonary metastasis were determined to be independent predictors conferring poorer prognosis, which suggests the effect of response to third-line treatment.

In this study, grade 3 or higher AE, namely hypertension, proteinuria, and diarrhea, were observed in approximately $10 \%$ of patients. These did not differ much from prior reports and none of the events was serious $(11,26)$.

Our study has several weaknesses, including its retrospective design and the limited number of patients from a single institution. Prospective investigation of clinical and molecular features in a large number of patients with locally advanced and metastatic RCC is required.

In conclusion, our results suggest that axitinib as secondline treatment is effective for patients with pulmonary metastasis alone of RCC. However, the role of axitinib as second-line treatment for patients with extrapulmonary metastasis must be explored by further investigations.

\section{References}

1 Chow WH, Devesa SS, Warren JL and Fraumeni JF Jr.: Rising incidence of renal cell cancer in the United States. JAMA 281: 1628-1631, 1999.

2 Marugame T, Kamo K, Katanoda K, Ajiki W and Sobue T: Cancer incidence and incidence rates in Japan in 2000: Estimates based on data from 11 population-based cancer registries. Jpn J Clin Oncol 36: 668-675, 2006.

3 Motzer RJ, Hutson TE, Tomczak P, Michaelson MD, Bukowski RM, Rixe O, Oudard S, Negrier S, Szczylik C, Kim ST, Chen I, Bycott PW, Baum CM and Figlin RA: Sunitinib versus interferon alfa in metastatic renal-cell carcinoma. N Engl J Med 356: 115124, 2007.

4 Motzer RJ, Hutson TE, Cella D, Reeves J, Hawkins R, Guo J, Nathan P, Staehler M, de Souza P, Merchan JR, Boleti E, Fife K, Jin J, Jones R, Uemura H, De Giorgi U, Harmenberg U, Wang J, Sternberg CN, Deen K, McCann L, Hackshaw MD, Crescenzo R, Pandite LN and Choueiri TK: Pazopanib versus sunitinib in metastatic renal-cell carcinoma. N Engl J Med 369: 722-731, 2013. 
5 Hudes G, Carducci M, Tomczak P, Dutcher J, Figlin R, Kapoor A, Staroslawska E, Sosman J, McDermott D, Bodrogi I, Kovacevic Z, Lesovoy V, Schmidt-Wolf IG, Barbarash O, Gokmen E, O'Toole T, Lustgarten S, Moore L, Motzer RJ and Global AT: Temsirolimus, interferon alfa, or both for advanced renal-cell carcinoma. N Engl J Med 356: 2271-2281, 2007.

6 Ueda K, Suekane S, Ogasawara N, Chikui K, Suyama S, Nakiri M, Nishihara K, Matsuo M and Igawa T: Long-term response of over ten years with sorafenib monotherapy in metastatic renal cell carcinoma: a case report. J Med Case Rep 10: 177, 2016.

7 Ueda K, Suekane S, Nishihara K, Ogasawara N, Kurose H, Hayashi S, Chikui K, Suyama S, Nakiri M, Matsuo M and Igawa $\mathrm{T}$ : Duration of first-line treatment with molecular targeted-therapy is a prognostic factor in metastatic renal cell carcinoma. Anticancer Res 35: 3415-3421, 2015.

8 Patard JJ, Pignot G, Escudier B, Eisen T, Bex A, Sternberg C, Rini B, Roigas J, Choueiri T, Bukowski R, Motzer R, Kirkali Z, Mulders P and Bellmunt J: ICUD-EAU International Consultation on Kidney Cancer 2010: Treatment of metastatic disease. Eur Urol 60: 684-690, 2011.

9 Rini BI, Escudier B, Tomczak P, Kaprin A, Szczylik C, Hutson TE, Michaelson MD, Gorbunova VA, Gore ME, Rusakov IG, Negrier S, Ou YC, Castellano D, Lim HY, Uemura H, Tarazi J, Cella D, Chen C, Rosbrook B, Kim S and Motzer RJ: Comparative effectiveness of axitinib versus sorafenib in advanced renal cell carcinoma (AXIS): A randomised phase 3 trial. Lancet 378: 1931-1939, 2011.

10 Motzer RJ, Bacik J, Murphy BA, Russo P and Mazumdar M: Interferon-alfa as a comparative treatment for clinical trials of new therapies against advanced renal cell carcinoma. J Clin Oncol 20: 289-296, 2002.

11 Miyake H, Harada KI, Ozono S and Fujisawa M: Assessment of efficacy, safety, and quality of life of 124 patients treated with axitinib as second-line therapy for metastatic renal-cell carcinoma: experience in real-world clinical practice in Japan. Clin Genitourin Cancer 15: 122-128, 2017.

12 Common Terminology Criteria for Adverse Events (CTCAE) v4.0. Available from http://ctep.cancer.gov/protocol Development/ electronic_applications/ctc.htm\#ctc_40. Last accessed Febrary 20, 2018.

13 Eisenhauer EA, Therasse P, Bogaerts J, Schwartz LH, Sargent D, Ford R, Dancey J, Arbuck S, Gwyther S, Mooney M, Rubinstein L, Shankar L, Dodd L, Kaplan R, Lacombe D and Verweij J: New response evaluation criteria in solid tumours: revised RECIST guideline (version 1.1). Eur J Cancer 45: 228247, 2009

14 Krajewski KM, Franchetti Y, Nishino M, Fay AP, Ramaiya N, Van den Abbeele AD and Choueiri TK: $10 \%$ Tumor diameter shrinkage on the first follow-up computed tomography predicts clinical outcome in patients with advanced renal cell carcinoma treated with angiogenesis inhibitors: a follow-up validation study. Oncologist 19: 507-514, 2014.

15 Heng DY, Xie W, Regan MM, Warren MA, Golshayan AR, Sahi C, Eigl BJ, Ruether JD, Cheng T, North S, Venner P, Knox JJ, Chi KN, Kollmannsberger C, McDermott DF, Oh WK, Atkins MB, Bukowski RM, Rini BI and Choueiri TK: Prognostic factors for overall survival in patients with metastatic renal cell carcinoma treated with vascular endothelial growth factor-targeted agents: results from a large, multicenter study. J Clin Oncol 27: 57945799, 2009.
16 Calvo E, Ravaud A and Bellmunt J: What is the optimal therapy for patients with metastatic renal cell carcinoma who progress on an initial VEGFR-TKI? Cancer Treat Rev 39: 366-374, 2013.

17 Miyake H, Imai S, Tamura K, Sugiyama T, Furuse H, Ozono S, and Fujisawa M: Comparison of tyrosine kinase inhibitor versus mammalian target of rapamycin Inhibitor as Second-line molecular-targeted therapy for patients with poor-risk metastatic renal cell carcinoma. Anticancer Res 37: 1523-1528, 2017.

18 Motzer RJ, Escudier B, McDermott DF, George S, Hammers HJ, Srinivas S, Tykodi SS, Sosman JA, Procopio G, Plimack ER, Castellano D, Choueiri TK, Gurney H, Donskov F, Bono P, Wagstaff J, Gauler TC, Ueda T, Tomita Y, Schutz FA, Kollmannsberger C, Larkin J, Ravaud A, Simon JS, Xu LA, Waxman IM and Sharma P: Nivolumab versus everolimus in advanced renal-cell carcinoma. $\mathrm{N}$ Engl J Med 373: 1803-1813, 2015.

19 Ueda T, Uemura H, Tomita Y, Tsukamoto T, Kanayama H, Shinohara N, Tarazi J, Chen C, Kim S, Ozono S, Naito S and Akaza H: Efficacy and safety of axitinib versus sorafenib in metastatic renal cell carcinoma: subgroup analysis of Japanese patients from the global randomized Phase 3 AXIS trial. Jpn J Clin Oncol 43: 616-628, 2013.

20 Seidel C, Busch J, Weikert S, Steffens S, Bokemeyer C and Grunwald V: Tumour shrinkage measured with first treatment evaluation under VEGF-targeted therapy as prognostic marker in metastatic renal cell carcinoma (mRCC). Br J Cancer 109: 29983004, 2013.

21 Miyake H, Harada K, Ozono S and Fujisawa M: Prognostic significance of early tumor shrinkage under second-line targeted therapy for metastatic renal cell carcinoma: A retrospective multiinstitutional study in Japan. Mol Diagn Ther 20: 385-392, 2016.

22 Ishihara H, Kondo T, Yoshida K, Omae K, Takagi T, Iizuka J and Tanabe K: Time to progression after first-line tyrosine kinase inhibitor predicts survival in patients with metastatic renal cell carcinoma receiving second-line molecular-targeted therapy. Urol Oncol 35: 542 e541-542 e549, 2017.

23 Li JR, Yang CK, Wang SS, Chen CS, Chiu KY, Cheng CL, Yang CR, Ho HC, Ko JL and Ou YC: First-line treatment result influence second-line regimen selection in targeted therapy for metastatic renal cell carcinoma. Anticancer Res 34: 5643-5647, 2014.

24 Miyazaki A, Miyake H, Harada K and Fujisawa M: No significant correlation of clinical outcomes between first-and second-line tyrosine kinase inhibitors in patients with metastatic renal cell carcinoma. Anticancer Res 35: 3067-3073, 2015.

25 Escudier B, Sharma P, McDermott DF, George S, Hammers HJ, Srinivas S, Tykodi SS, Sosman JA, Procopio G, Plimack ER, Castellano D, Gurney H, Donskov F, Peltola K, Wagstaff J, Gauler TC, Ueda T, Zhao H, Waxman IM and Motzer RJ: CheckMate 025 randomized phase 3 study: Outcomes by key baseline factors and prior therapy for nivolumab versus everolimus in advanced renal cell carcinoma. Eur Urol 72: 962-971, 2017.

26 Matias M, Le Teuff G, Albiges L, Guida A, Brard C, Bacciarelo G, Loriot Y, Massard C, Lassau N, Fizazi K and Escudier B: Real world prospective experience of axitinib in metastatic renal cell carcinoma in a large comprehensive cancer centre. Eur J Cancer 79: 185-192, 2017. 